\title{
Citotoxicidad y genotoxicidad en células humanas expuestas in vitro a glifosato
}

\author{
Claudia Milena Monroy, Andrea Carolina Cortés, Diana Mercedes Sicard, \\ Helena Groot de Restrepo \\ Laboratorio de Genética Humana, Universidad de los Andes, Bogotá, D. C., Colombia.
}

Introducción. El glifosato es un herbicida de amplio espectro, no selectivo, utilizado para eliminar malezas indeseables en ambientes agrícolas y forestales. La acción herbicida corresponde a la inhibición de la biosíntesis de aminoácidos aromáticos en las plantas. Al no ser este mecanismo compartido por los seres humanos es considerado como de bajo riesgo para la salud de los mismos. Sin embargo, investigaciones recientes indican que puede alterar otros procesos celulares en animales lo que puede presentar un factor de riesgo a nivel ambiental y de salud en las zonas donde se emplea este herbicida.

Objetivo. El objetivo del presente estudio fue evaluar la citotoxicidad y la genotoxicidad del glifosato en células humanas normales (GM38) y en células humanas de fibrosarcoma (HT1080). Materiales y métodos. La citotoxicidad aguda y crónica se determinó al exponer las células en cultivo a diferentes concentraciones de glifosato, y se analizó la viabilidad celular con cristal violeta y colorante de exclusión azul de tripano, respectivamente. La genotoxicidad se determinó por medio del ensayo del cometa y los datos se analizaron usando la prueba de Dunnet.

Resultados. En la citotoxicidad crónica las células GM38 y las HT1080 presentaron un efecto dependiente de la dosis después del tratamiento con glifosato en concentraciones de 5,2 a 8,5 $\mathrm{mM}$ y 0,9 a 3,0 mM, respectivamente. En la citotoxicidad aguda, las células GM38 y las HT1080 expuestas a un rango de concentraciones de 4,0 a $7,0 \mathrm{mM}, 4,5$ a $5,75 \mathrm{mM}$ y 4,0 a $7,0 \mathrm{mM}$, respectivamente, presentaron una viabilidad mayor al $80 \%$. Se evidenció daño en el ADN después del tratamiento con glifosato en concentraciones de 4,0 a 6,5 mM para las células GM38 y de 4,75 a 5,75 mM para las células HT1080.

Conclusiones. Se sugiere que el mecanismo de acción del glifosato no se limita únicamente a las plantas sino que puede alterar la estructura del ADN en otros tipos de células como son las de los mamíferos.

Palabras clave: herbicidas, citotoxicidad, genotoxicidad, ensayo cometa.

\section{Cytotoxicity and genotoxicity of human cells exposed in vitro to glyphosate}

Introduction. Glyphosate is a broad-spectrum non-selective herbicide, used to eliminate unwanted weeds in agricultural and forest settings. Herbicide action is achieved through inhibition of aromatic amino acid biosynthesis in plant cells. Since this is not a conserved mechanism between human and plant cells, glyphosate is considered to be a low health risk substance for humans. However, the occurrence of possible harmful side effects of glyphosate use is not well documented and controversial. Toxicity and genotoxicity studies indicate that glyphosate is not harmful, although several investigations suggest that it can alter various cellular processes in animals. Therfore this has potential as a health and environmental risk factor in areas where glyphosate is widely used.

Objectives. The present study evaluated glyphosate cytotoxic and genotoxic effects in normal human cells (GM38) and human fibrosarcoma (HT1080) cells.

Materials and methods. Acute and chronic cytotoxicity were determined through the exposure of cultured cells to graded concentrations of glyphosate, and cell viability analysis was performed with crystal violet and Trypan blue staining. Genotoxicity was determined using the comet assay and data significance was evaluated with Dunnet's test. 
Results. For chronic cytotoxicity a dose-dependent effect was observed in both GM38 and HT1080 cells after treatment with 5.2-8.5 mM and 0.9-3.0 mM glyphosate, respectively. In the acute cytotoxicity study, GM38 cells exposed to $4.0-7.0 \mathrm{mM}$ glyphosate and HT1080 cells exposed to $4.5-5.8 \mathrm{mM}$ glyphosate, had cell viability counts higher than $80 \%$. Genotoxic effects were evidenced in GM38 cells at glyphosate concentrations of 4.0-6.5 mM and in HT1080 cells at glyphosate concentrations of $4.75-5.75 \mathrm{mM}$.

Conclusions. The levels of cytotoxicity and genotoxicity of glyphosate occurring in mammalian cells suggested that its mechanism of action is not limited to plant cells.

Keywords: herbicides, cytotoxicity, genotoxicity, comet assay

El glifosato, un ácido orgánico débil cuya molécula está formada por una fracción de glicina y otra de fosfonometil ( $\mathrm{N}$ - fosfonometilglicina), $\mathrm{C}_{3} \mathrm{H}_{8} \mathrm{NO}_{5}$ es un herbicida de amplio espectro, no selectivo, utilizado para eliminar malezas indeseables en ambientes agrícolas y forestales, especialmente en cultivos de maíz, soya y arroz (1). La aplicación de este herbicida produce la inhibición de aminoácidos aromáticos en la planta por inactivación de la enzima 5-enolpiruvilchiquimato3-fosfato sintasa (2-3). Esta enzima no existe en animales y, en consecuencia, la citotoxicidad del glifosato es considerada relativamente baja o inexistente en humanos. De acuerdo con la clasificación de la Agencia de Protección Ambiental (EPA) de los Estados Unidos, el glifosato se encuentra incluido en el grupo $D$, es decir, "el agente probablemente no es carcinogénico para el ser humano"; esto, basado en la evidencia de oncogenicidad en animales (4). En algunos estudios el glifosato no presentó mutagenicidad en células $\mathrm{CHO}$ (Chinese Hamster Ovary), Salmonella sp. y Escherichia coli; mostró resultados negativos en ensayos de reparación en Bacillus subtilis y en cultivos primarios de hepatocitos (5). Así mismo, un estudio sobre la evaluación del riesgo del Roundup ${ }^{\circledR}$, formulación comercial cuyo principal componente es el glifosato, concluyó que este herbicida no constituye un riesgo en la salud de las personas expuestas a este químico. En este estudio se analizó la genotoxicidad, el potencial tumorogénico

\footnotetext{
Correspondencia:

Helena Groot de Restrepo, Carrera 1를 No.18-A-10, Bogotá, D. C., Colombia

Telephone: +(57) 1 339-4949, extensión 2755: fax: + (57)1 339-4949, extensión 2817 hgroot@uniandes.edu.co

Recibido:13/12/04; aceptado: 07/06/05
}

y los efectos en la fertilidad en modelos animales (6). No obstante, investigaciones recientes muestran otro panorama, un estudio cuyo modelo eran roedores en estado de gestación y sus fetos, mostró una inducción de anormalidades funcionales en enzimas citosólicas como la isocitrato deshidrogenasa, la glucosa-6-fosfato deshidrogenasa en los animales que fueron expuestos a diferentes concentraciones de glifosato (7). En otras investigaciones se evidenciaron cambios morfológicos en el citoesqueleto y retardo en el desarrollo de roedores (8). En otro estudio, en el cual se expusieron renacuajos a diferentes concentraciones de Roundup $^{\circledR}$, la prueba del cometa mostró daño en el ADN directamente proporcional a la dosis utilizada (9).

La balanza parece inclinarse hacia el lado de calificar al glifosato como un herbicida de riesgo potencial bajo para la salud de los animales y de los seres humanos; sin embargo, la controversia persiste y, especialmente, en algunos países como Colombia, donde este herbicida es ampliamente utilizado en regiones forestales en la erradicación de cultivos ilícitos como parte del proceso antidrogas y como desecante de los cultivos de caña de azúcar. A este respecto, es importante avanzar en el conocimiento sobre la genotoxicidad y la citotoxicidad de este herbicida para aportar información que ayude a esclarecer la discusión en torno a sus efectos.

Una metodología que ha sido ampliamente utilizada por diversos laboratorios para evaluar el potencial genotóxico de los agentes químicos, los compuestos industriales y las nuevas drogas (1014) es el ensayo del cometa alcalino o electroforesis de células individuales $(\mathrm{pH}>13)$. Ésta es una técnica sensible que detecta 
rompimientos de cadena sencilla, sitios alcalilábiles y sitios de reparación por escisión de bases incompleta (15). Además de esta técnica, se implementó el cultivo celular en microplacas, lo cual permite la evaluación simultánea de varias réplicas por tratamiento (16-18). El objetivo del presente estudio fue evaluar la citotoxicidad y la genotoxicidad del glifosato en células humanas normales (GM38) y en células humanas de fibrosarcoma (HT1080) por medio del ensayo del cometa en microplacas de 96 pozos.

\section{Materiales y métodos}

\section{Líneas celulares}

HT1080: fibrosarcoma humano (ATCC No: CCL121); línea celular normal y eficiente en el sistema de reparación por escisión de nucleótidos.

GM38: fibroblastos humanos primarios (NIGMS Human Genetic Cell Repository, Coriell Institute for Medical Research, NJ, USA); línea celular normal y eficiente en el sistema de reparación por escisión de nucleótidos.

\section{Condiciones del cultivo}

Las líneas celulares humanas de fibrosarcoma HT1080 y de fibroblastos normales GM38 se cultivaron en medio DMEM (Dulbeco's Modified Eagle's Medium, Sigma), con suplemento de 5\% de suero bovino fetal (Gibco), $1 \%$ de penicilina/ estreptomicina (Gibco), 2\% de glutamina (Gibco) y $2,2 \%$ de bicarbonato de sodio. Las células se mantienen a $37^{\circ} \mathrm{C}$ en una atmósfera húmeda con $5 \% \mathrm{CO} 2$.

\section{Glifosato}

El glifosato que se empleó en este estudio es de grado técnico (Sigma Chemical Co., CAS 1071836). La solución de trabajo tuvo una concentración de $25 \mathrm{mM}$ (1 g de glifosato/236,4 $\mathrm{mL}$ de agua destilada estéril) y se mantuvo a una temperatura de $4^{\circ} \mathrm{C}$.

\section{Concentraciones de glifosato- ensayos preliminares}

Para encontrar el rango de concentraciones de glifosato por utilizar se llevó a cabo un ensayo preliminar, en el que se expusieron células $\mathrm{CHO}$ a diferentes concentraciones de glifosato, incrementando las concentraciones $0,1 \mathrm{mM}$ en un rango de 0,1-3,7 mM. Se realizaron varios ensayos para determinar el rango de exposición en las células HT1080 y se observó un efecto dosis-respuesta en un rango de concentraciones de 0,9 a 3,3 mM (19). De la misma forma, para la línea celular GM38 se partió de la primera concentración de 0,9 mM, pero a diferencia de las células HT1080, se encontró que el efecto dosis respuesta se presentó en un rango de 5,0 a $8,5 \mathrm{mM}$. Los resultados de estos ensayos fueron los mismos en las 8 réplicas realizadas para cada concentración.

\section{Citotoxicidad crónica y aguda}

Para las pruebas de citotoxicidad crónica y aguda se utilizó la metodología establecida por otros autores en microplacas de 96 pozos (16-18) en la evaluación de diferentes agentes químicos.

\section{Citotoxicidad crónica}

Las microplacas de 96 pozos están divididas en 12 columnas y 8 filas; cada columna representa un tratamiento y cada una de las filas, las réplicas de ese tratamiento. La columna 1 se empleó como blanco y contenía $200 \mu \mathrm{l}$ de DMEM suplementado. La columna 2 se empleó como control negativo y contenía $100 \mu \mathrm{l}$ de suspensión de células $\left(3 \times 10^{3}\right.$ células $\left./ \mathrm{ml}\right)$ más $100 \mu \mathrm{L}$ DMEM de suplemento. Los pozos de las columnas restantes contenían $100 \mu \mathrm{l}$ de una suspensión celular de $3 \times 10^{3}$ células $/ \mathrm{ml}$ a las cuales se les adicionó el glifosato en concentraciones crecientes, 0,9 a 8,5 mM para las células GM38 y de 0,6 a 3,3 mM para las células HT1080, el volumen se completó a $200 \mu \mathrm{l}$ con medio suplementado en cada pozo. Posteriormente se sometió la microplaca a agitación orbital durante 15 minutos a $37^{\circ} \mathrm{C}$ para garantizar la distribución homogénea de las células y del glifosato en cada pozo. Luego, se incubó a $37^{\circ} \mathrm{C}$ en atmósfera húmeda con $5 \%$ de $\mathrm{CO}_{2}$ durante 72 horas. Después de las 72 horas de incubación, se retiró el medio de cada pozo y se adicionaron $20 \mu \mathrm{lde}$ metanol al $100 \%$ por 15 minutos y $15 \mu \mathrm{l}$ de cristal violeta (solución al $1 \%$ de cristal violeta en $50 \%$ de metanol) por 30 minutos. Posteriormente, las placas fueron lavadas con agua destilada y se les adicionó en cada pozo $50 \mu$ l de dimetilsulfóxido 
(DMSO) por 30 minutos. La densidad celular (viabilidad celular) se determinó en un lector de micro placas (BIORAD) y con una longitud de onda de $595 \mathrm{~nm}$.

\section{Citotoxicidad aguda}

En la microplaca de 96 pozos se sembraron 100 $\mu l$ de suspensión de células en una concentración de $3 \times 10^{5}$ células $/ \mathrm{ml}$ y $100 \mu \mathrm{l}$ de medio DMEM con $5 \%$ de SBF en cada pozo; posteriormente, se incubó durante 24 horas a $37^{\circ} \mathrm{C}$ en atmósfera húmeda con $5 \%$ de $\mathrm{CO}_{2}$. En el presente análisis se utilizó un título más alto que en el ensayo anterior $\left(3 \times 10^{3}\right.$ células $\left./ \mathrm{ml}\right)$, para garantizar una concentración adecuada de células en un tiempo más corto de incubación antes de la exposición al glifosato (citotoxicidad crónica, 72 horas; aguda, 24 horas).

Luego de la incubación se aspiró el medio y se lavó cada pozo con $50 \mu \mathrm{L}$ de solución salina tampón (PBS-1X). Posteriormente, se adicionó el medio con suplemento (libre de suero bovino fetal) más las concentraciones de glifosato en un rango entre 4,0 y $6,5 \mathrm{mM}$ para las dos líneas celulares, para un total de $25 \mu$ l en cada pozo. El control positivo fueron células expuestas a una concentración de $50 \mathrm{ug} / \mathrm{ml}$ de etopósido VP 16 (Sigma) y el control negativo fueron células tratadas con DMEM con suplemento, sin exposición al químico. Se incubó la microplaca durante 4 horas a $37^{\circ} \mathrm{C}$ de acuerdo con el protocolo establecido $(11,12)$ en agitación orbital $\mathrm{y}$, posteriormente, se le adicionaron $50 \mu \mathrm{l}$ de tripsina (solución 1:10 - 0,1\% tripsina: PBS 1X) a cada pozo para desprender las células, se incubó nuevamente por 5 minutos a $37^{\circ} \mathrm{C}$ y se adicionaron $100 \mu \mathrm{l}$ de DMEM con suplemento. A continuación se realizó el conteo de las células vivas y muertas por exclusión con azul de tripano en una cámara de Newbauer para determinar el porcentaje de viabilidad celular. En esta prueba se realizaron varios ensayos para establecer el rango de concentraciones en el cual la viabilidad celular fuera mayor al $80 \%$ y, con base en estos rangos, desarrollar los estudios de genotoxicidad.

\section{Ensayo del cometa}

Luego de la exposición de las células a diferentes concentraciones de glifosato durante 4 horas en microplacas de 96 pozos, se tomaron $100 \mu \mathrm{lde}$ la suspensión celular de cada pozo, se le adicionaron $900 \mu \mathrm{l}$ de agarosa de bajo punto de fusión $(0,5 \%)$ y se colocaron $100 \mu \mathrm{l}$ de la mezcla sobre una lámina portaobjetos que contenía una capa de agarosa de punto de fusión normal (1\%). Posteriormente, las láminas se expusieron durante 24 horas a una solución de lisis $(\mathrm{NaCl} 0,23 \mathrm{M}$, EDTA $9 \mathrm{mM}$, tris $0,9 \mathrm{mM}$, tritón $\mathrm{X}-100$ al $1 \%$ y DMSO al $10 \%$ ) a $4^{\circ} \mathrm{C}$. Antes de la electroforesis alcalina las láminas se ubicaron en la cámara de electroforesis horizontal, se les adicionó el tampón de electroforesis $(\mathrm{NaOH} 300 \mathrm{mM}$ y EDTA $1 \mathrm{mM}$ $\mathrm{pH}>13$ ) y se dejaron en reposo, aproximadamente, 25 minutos a $4^{\circ} \mathrm{C}$. Luego, se corrió la electroforesis a $290 \mathrm{~mA}$ y $25 \mathrm{~V}$ durante 35 minutos. Posteriormente, se adicionó el tampón neutralizante $(400 \mathrm{mM}$ Tris $\mathrm{HCl}-\mathrm{pH} 7,5)$ y las láminas se tiñeron con $65 \mu \mathrm{l}$ de bromuro de etidio $(2 \mu \mathrm{g} / \mathrm{ml})$. Las láminas se analizaron usando el microscopio de fluorescencia Zeiss con un filtro de excitación BP 546/10 nm y un filtro de barrido de $590 \mathrm{~nm}$. Se leyeron 25 células por lámina, tomando en cuenta la longitud de migración del ADN -se inicia la medición en el centro del núcleo hasta el último punto de migración- y la morfología de los núcleos al clasificarlos en una de cinco categorías: a) no daño en el ADN, b) daño bajo, c) daño medio, d) daño alto y e) daño total (20). En la figura 1 se señala la medida de la longitud de migración del ADN en micras y en la figura 2, las diferentes categorías de clasificación.

\section{Análisis estadístico}

Los datos se analizaron usando la prueba de correlación de Pearson para determinar la

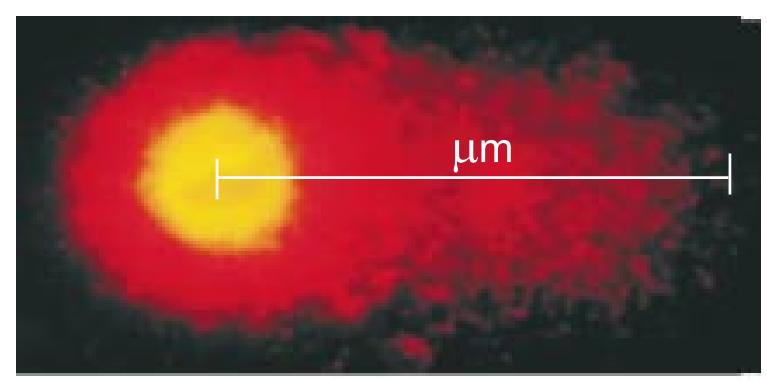

Figura 1. Longitud de la cola del cometa o migración del ADN medida en micras. Longitud de la migración del ADN en micras $(\mu \mathrm{m})$, desde el centro del núcleo hasta el último punto de fluorescencia, en 25 células/lámina. 

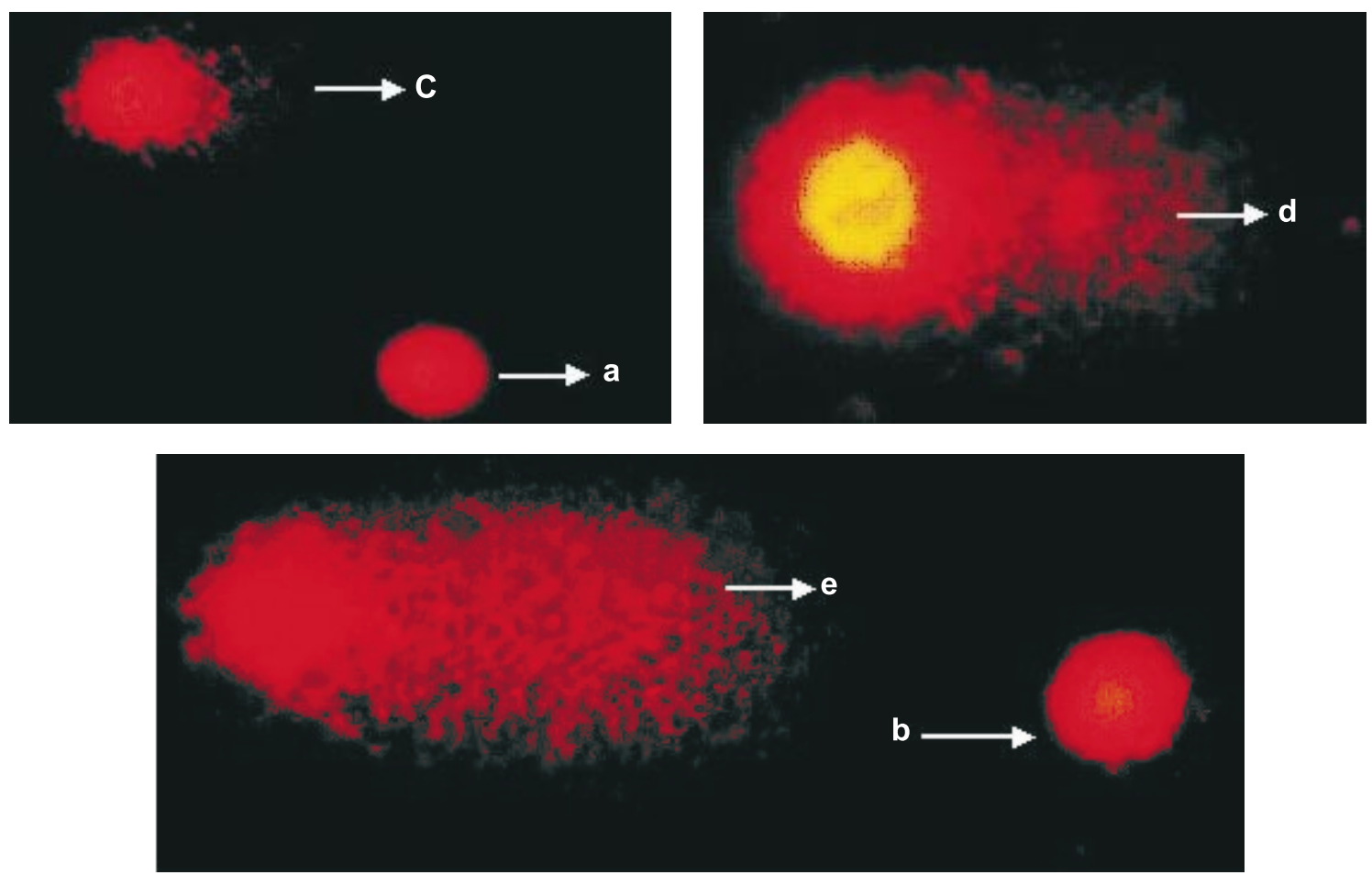

Figura 2. Clasificación de la morfología de los núcleos en el ensayo del cometa. Morfología de los núcleos al clasificarlos en una de cinco categorías: a) sin daño en el ADN, b) daño bajo, c) daño medio, d) daño alto y e) daño total (20) en 25 células/lámina.

correlación entre la viabilidad celular y las 16 réplicas de cada concentración de glifosato evaluadas. La prueba de Shapiro-Wilk (SPSS, version 10.0) se utilizó para determinar si los resultados presentaban distribución normal y ANOVA one way-Dunnet's test (Sigma Stat 2.0) para determinar si la morfología y el promedio de longitud presentaban diferencias significativas entre el control negativo y las concentraciones de glifosato evaluadas.

\section{Resultados}

En la figura 3 se muestran las curvas entre las concentraciones de glifosato y el promedio del porcentaje de viabilidad celular después de 72 horas de exposición en 16 réplicas por tratamiento. El análisis de Pearson mostró una correlación negativa significativa en las dos líneas celulares evaluadas entre las concentraciones de glifosato y la viabilidad celular en un tiempo prolongado de exposición (72 horas). En las células GM38 se presenta la correlación en un rango de concentraciones de 5,2 a $8,5 \mathrm{mM}(\mathrm{r}=-0,906$, $\mathrm{P}<0,05)$ y en las células HT1080, en un rango de concentraciones de 0,6 a 3,3 mM $(r=-0,994$, $\mathrm{P}<0,05)$. Así mismo, la viabilidad celular en las células GM38 se reduce al $80 \%$ cuando las células se exponen a dosis de $5,5 \mathrm{mM}$ y al $50 \%$ a una concentración de $6,9 \mathrm{mM}$ de glifosato, lo que indica que al aumentar la concentración de glifosato la viabilidad celular se ve afectada de manera negativa. De igual forma, en las células HT1080 la viabilidad celular se reduce al $80 \%$ cuando las células se exponen a dosis de 0,6 $\mathrm{mM}$ y al $50 \%$ a una concentración de $1,7 \mathrm{mM}$ de glifosato. El coeficiente de determinación, basado en la correlación de Pearson, en las células GM38 $\left(r^{2}=0,82\right)$ y en las células HT1080 $\left(r^{2}=0,99\right)$ es del $82 \%$ y del $99 \%$, respectivamente.

En la figura 4 se muestran las curvas entre las concentraciones de glifosato y la viabilidad celular después de 4 horas de exposición, en 16 réplicas por tratamiento. La correlación entre la viabilidad 
(a) Células GM38

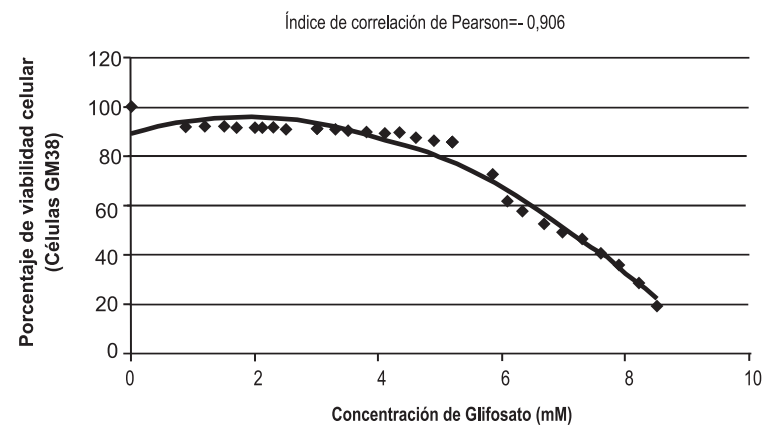

(b) Células HT1080

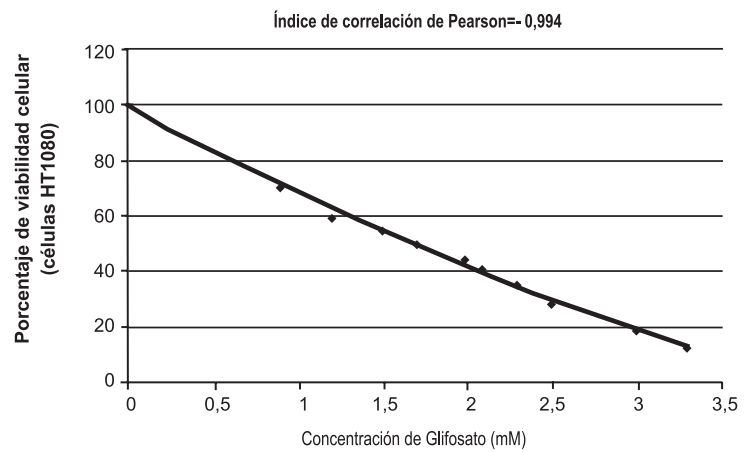

Figura 3. Citotoxicidad crónica en células GM38 (a) y células HT1080 (b). Porcentaje de viabilidad celular a las 72 horas de exposición al herbicida, en GM38 (28 concentraciones, 16 réplicas por concentración) y en HT1080 (11 concentraciones, 16 réplicas por concentración); (a) células GM38, (b) células HT1080.

celular y la dosis de glifosato es significativa cuando las células se exponen a concentraciones altas de glifosato en un periodo corto de exposición (4 horas). En las células GM38 se presenta la correlación en un rango de concentraciones de 4,0 a $6,5 \mathrm{mM}(r=-0,924, P<0,05)$ y en las células $\mathrm{HT} 1080$ en un rango de concentraciones de $4,5 \mathrm{a}$ $6,5 \mathrm{mM}(\mathrm{r}=-0,945, \mathrm{P}<0,05)$. En las células $\mathrm{GM} 38$ se presenta una viabilidad celular mayor al $80 \%$ en un rango de concentraciones de 4,0 a 6,5 mM, y en las células HT1080, en un rango de concentraciones de 4,5 a 5,75 mM.

En los cuadros 1 y 2 se muestra el daño en el ADN (longitud de la cola) inducido por glifosato en las dos líneas celulares. Se evidencia un daño significativo en el ADN, con respecto al control negativo, tanto en las células $\mathrm{GM} 38\left(\mathrm{~F}_{8,71}=102,34\right.$,

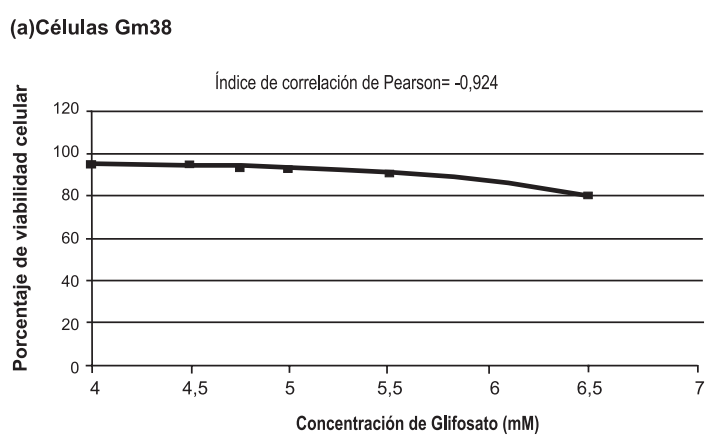

(b)Células HT1080

Índice de correlación de Pearson $=-0,945$

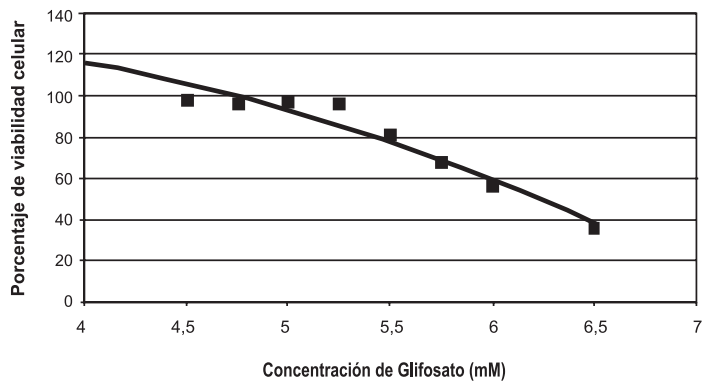

Figura 4. Citotoxicidad aguda en células GM38 (a) y células HT1080 (b). Porcentaje de viabilidad celular a las 4 horas de exposición al herbicida, en GM38 (6 concentraciones, 16 réplicas por concentración) y en HT1080 (8 concentraciones, 16 réplicas por concentración); (a) células GM38, (b) células HT1080.

$\mathrm{P}<0,001)$ como en las células HT1080 $\left(F_{8,142}=91,26, P<0,001\right)$, cuando se exponen en un período de tiempo corto (4 horas) a concentraciones altas de glifosato. En las células GM38 en concentraciones de 4,0 a $6,5 \mathrm{mM}$ y en las células HT1080 en concentraciones de 4,75 a 5,75 mM. En la figura 5 se muestra el daño en el ADN (morfología del cometa) inducido por glifosato en las dos líneas celulares. Al igual que en la medición del daño en el ADN con la longitud de la cola, se presentan diferencias significativas $(P<0,001)$ con respecto al control negativo en la morfología del cometa.

\section{Discusión}

Múltiples estudios in vivo e in vitro desarrollados para esclarecer el potencial tóxico o genotóxico 
Cuadro 1. Prueba de Dunnet. Migración del ADN $(\mu \mathrm{m})$ en células GM38 expuestas a glifosato.

\begin{tabular}{lcc}
\hline $\begin{array}{l}\text { Concentración de } \\
\text { glifosato }(\mathbf{m M})\end{array}$ & $\begin{array}{c}\text { Migración del ADN }(\mu \mathrm{m}) \\
\text { mediana }( \pm \mathrm{DE})\end{array}$ & $\begin{array}{c}\text { Migración del ADN }(\mu \mathrm{m}) \\
\text { promedio }( \pm \mathrm{DE})\end{array}$ \\
\hline 0 & $12,50 \pm 0,92$ & $15,79 \pm 1,05$ \\
4 & $12,75 \pm 1,48$ & $19,47 \pm 1,80^{* * *}$ \\
4,5 & $17,12 \pm 3,68^{* * *}$ & $21,20 \pm 1,55^{* * *}$ \\
4,75 & $36,37 \pm 3,54^{* * *}$ & $38,23 \pm 2,27^{* * *}$ \\
5 & $42,00 \pm 2,61^{* * *}$ & $48,26 \pm 2,39^{* * *}$ \\
5,5 & $42,00 \pm 1,51^{* * *}$ & $47,20 \pm 2,94^{* * *}$ \\
6,5 & $80,75 \pm 13,64^{* * *}$ & $87,97 \pm 14,10^{* * *}$ \\
Control positivo (VP 16) & $89,33 \pm 8,86^{* * *}$ & $96,38 \pm 8,85^{* * *}$ \\
Valor estadístico, prueba de Dunnet & $\mathrm{F} 8,71=53,47$ & $\mathrm{~F} 8,71=102,34$ \\
\hline
\end{tabular}

$P<0,001^{*}$

$\mathrm{P}<0,05$ **

Los datos corresponden a la mediana y el promedio de la migración del ADN o longitud de la cola \pm desviación estándar (DE) mediante el ANOVA (one way-Dunnet's test).

Cuadro 2. Prueba de Dunnet. Migración del ADN ( $\mu \mathrm{m})$ en células HT1080 expuestas a glifosato.

\begin{tabular}{lcc}
\hline $\begin{array}{l}\text { Concentración de } \\
\text { glifosato }(\mathbf{m M})\end{array}$ & $\begin{array}{c}\text { Migración del ADN }(\mu \mathrm{m}) \\
\text { mediana }( \pm \mathrm{DE})\end{array}$ & $\begin{array}{c}\text { Migración del ADN }(\mu \mathrm{m}) \\
\text { promedio }( \pm \mathrm{DE})\end{array}$ \\
\hline 4,5 & $24,25 \pm 2,75$ & $27,18 \pm 2,409$ \\
4,75 & $25,75 \pm 1,43$ & $29,16 \pm 1,92^{* * *}$ \\
5 & $26,62 \pm 2,78$ & $29,11^{* *} \pm 3,19^{* * *}$ \\
5,25 & $24,25 \pm 1,37^{* * *}$ & $27,81^{* *} \pm 2,07^{* *}$ \\
5,5 & $27,50 \pm 3,37^{* * *}$ & $31,28 \pm 2,96^{* * *}$ \\
5,75 & $31,12 \pm 2,62^{* * *}$ & $35,87 \pm 3,88^{* * *}$ \\
6 & $44,12 \pm 9,40^{* * *}$ & $49,38 \pm 11,24^{* * *}$ \\
6,5 & $58,00 \pm 13,26^{* * *}$ & $65,84 \pm 11,00^{* * *}$ \\
Control positivo (VP 16) & $109,50 \pm 6$ & $110,72 \pm 5,88$ \\
Valor estadístico, prueba de Dunnet & $\mathrm{F} 8,142=39,17$ & $\mathrm{~F} 8,142=91,26$ \\
\hline
\end{tabular}

\section{$P<0,001^{*}$}

$\mathrm{P}<0,05$ **

Los datos corresponden a la mediana y al promedio de la migración del ADN o longitud de la cola \pm desviación estándar (DE) mediante el ANOVA (one way-Dunnet's test).

del glifosato, tan ampliamente utilizado a nivel mundial, han clasificado este herbicida como de riesgo bajo en la salud de los animales y de los seres humanos; sin embargo, algunos autores han reportado resultados contradictorios. A este respecto, algunas agencias de regulación ambiental y algunas organizaciones o instituciones científicas internacionales plantean, en diferentes informes, que los resultados contradictorios pueden ser consecuencia de las dosis utilizadas y de la baja sensibilidad de las técnicas para determinar el impacto del glifosato $(5,21-23)$. En el presente trabajo se implementó la metodología para medir la citototoxicidad aguda y crónica, y la genotoxicidad en placas de 96 pozos, la cual fue de gran utilidad, ya que permitió establecer una correlación entre la dosis, el tiempo de exposición y las alteraciones en el ADN, así como detectar bajos niveles de daño en el genoma a bajas concentraciones (15). Al evaluarse la citotoxicidad crónica, la correlación de Pearson muestra una dependencia negativa entre la dosis de glifosato y la viabilidad celular, es decir, un incremento en la tasa de muerte celular al aumentar la dosis en un tiempo constante y prolongado de exposición. Así mismo, al evaluar el coeficiente de determinación se observa que la variabilidad en la viabilidad celular, correspondiente al $82 \%$ en células GM38 y $99 \%$ en células HT1080, es consecuencia de la exposición al glifosato. 
a) Células GM38

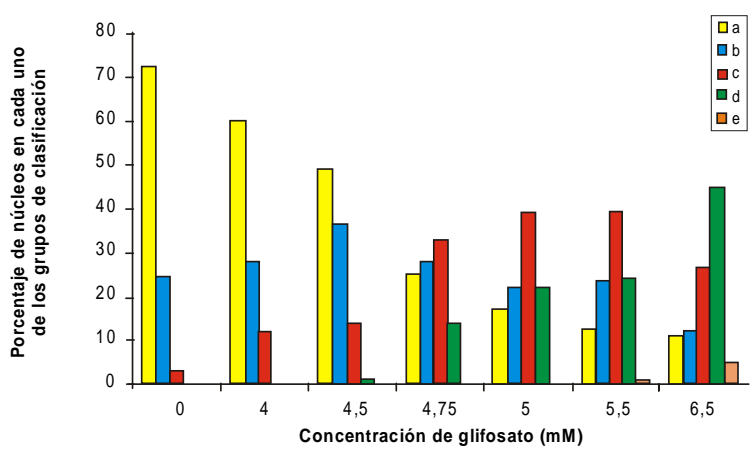

b) Células HT1080

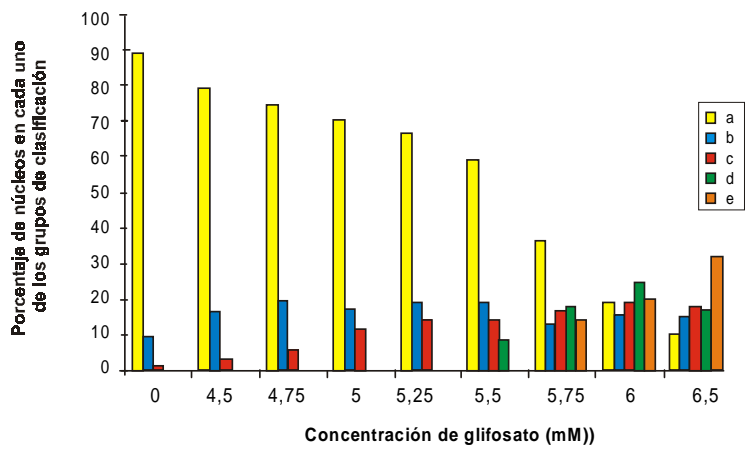

Figura 5. Daño en el ADN en las líneas celulares GM38 (a) y HT1080 (b), evaluado mediante la morfología de los núcleos. Porcentaje de núcleos en cada uno de los grupos de clasificación: a, b, c, d y e (125 núcleos analizados); a) células GM38, b) células HT1080. Morfología del núcleo según Anderson et al., 1994: a) sin daño en el ADN, b) daño bajo, c) daño medio, d) daño alto y e) daño total.

La disminución en la viabilidad celular, evaluada con azul de tripano o con cristal violeta, puede ser causada por la inducción de daños estructurales o alteraciones en las funciones básicas celulares que conducen a la muerte celular por apoptosis o necrosis (24). Al comparar las dos líneas celulares se observó una mayor sensibilidad en las células de fibrosarcoma humano HT1080 cuando se exponían a glifosato que en las células de fibroblastos humanos normales GM38, puesto que fue necesario aumentar de 5 a 9 veces la concentración de este herbicida en las células GM38 para obtener el mismo efecto que en las células HT1080. Esto indica que distintos tipos de células tienen sensibilidad variable al mismo compuesto, por lo cual sería de interés elucidar los mecanismos mediante los cuales las células presentan distintos niveles de respuesta a este compuesto.

Los análisis para determinar la citotoxicidad aguda mostraron un efecto dosis-respuesta en las dos líneas celulares, pero al igual que en la citotoxicidad crónica, las células HT1080 presentaron una mayor disminución en la viabilidad celular cuando se expusieron a las mismas concentraciones de glifosato que las células GM38. Cuando las células HT1080 se expusieron a la concentración más alta de glifosato $(6,5 \mathrm{mM})$ la viabilidad celular disminuyó hasta el $39 \%$, y en las células GM38 hasta el 79\%. Las características fisicoquímicas intrínsecas de cada línea celular pueden explicar las diferencias observadas en la viabilidad celular. Las células HT1080 presentan una clase de enzimas proteolíticas denominadas metaloproteasas de membrana (MPP), que están involucradas en la degradación de los componentes principales de la matriz extracelular y la membrana basal, facilitando, de esa forma, la proliferación celular, la adhesividad celular y la activación de factores de crecimiento. La inhibición de estas enzimas promueve el inicio del proceso de apoptosis celular. Diferentes trabajos realizados con esta línea celular muestran una correlación entre la disminución en la viabilidad celular y la expresión de MPP cuando se exponen a diferentes dosis de compuestos considerados potencialmente antineoplásicos (25-27). Teniendo en cuenta que las células normales no poseen este tipo de enzimas, se podría sugerir que el glifosato inhibe en las células HT1080 la expresión de MPP y, en consecuencia, se produce una disminución en la viabilidad celular a dosis menores que en las células GM38.

Al evaluar la genotoxicidad del glifosato en las dos líneas celulares, se observó un incremento significativo en el daño en el ADN en los dos parámetros evaluados: la longitud de la cola del cometa o migración del ADN, y la morfología del cometa. La longitud de la cola del cometa medida en micras presentó un incremento respecto al control negativo, en un rango de concentraciones de 4,0 a 6,5 mM en las células GM38 y de 4,75 a $5,75 \mathrm{mM}$ en las células HT1080. De la misma forma, la morfología de los núcleos mostró un 
incremento del daño en el mismo rango de concentraciones que al evaluar la migración del ADN. Los resultados obtenidos después de la exposición de las células GM38 a glifosato en ocho concentraciones, mostraron que el daño es proporcional a la dosis. En la concentración más baja $(4,0 \mathrm{mM})$ se observó un aumento del $4 \%$ en la clasificación b (daño bajo) y una aumento del $9 \%$ en la clasificación c (daño medio); así mismo, en la concentración más alta se observó un aumento del $45 \%$ en la clasificación d (daño alto), y del $5 \%$ en la clasificación e (daño total) con respecto al control. En las células HT1080 en la concentración más baja $(4,75 \mathrm{mM})$ se evidenció un aumento del $10 \%$ en la clasificación b y del 5 en la clasificación c; en la concentración más alta $(5,75 \mathrm{mM})$ se incrementó el $18 \%$ en la clasificación d y el $14 \%$ en la clasificación e. Estudios anteriores realizados en las células HT1080 han establecido que éstas son eficientes en la función del gen p53 (28), al igual que las células normales. Este gen es requerido para el funcionamiento adecuado de la reparación genómica global, una subvía de la reparación por escisión de nucleótidos, mecanismo básico para eliminar una amplia gama de daños en el ADN producidos por diferentes agentes (29). Los resultados de genotoxicidad indican que las células HT1080 son más susceptibles al daño en el ADN inducido por glifosato que las células GM38; sin embargo, en un estudio que se adelanta en la actualidad sobre la reparación del ADN (mismo grupo de investigación), los resultados preliminares muestran que ambas líneas celulares son eficientes en su capacidad de reparación, lo que sugiere que la capacidad de reparación del ADN por escisión de nucleótidos no se ve afectada como consecuencia de la exposición al glifosato y que, posiblemente, es otro el mecanismo de la reparación genómica global del ADN el que se ve afectado.

La genotoxicidad del glifosato ha sido evaluada por varios autores, principalmente mediante pruebas citogenéticas (aberraciones cromosómicas, intercambios entre cromátidas hermanas y frecuencia de micronúcleos), y pruebas para medir mutaciones (prueba de Ames, y mutaciones reversas en el locus HGPRT) en diferentes tipos celulares. La mayoría muestran al glifosato como un compuesto no genotóxico (30-33). Sin embargo, algunos trabajos muestran resultados diferentes (34-36). Los resultados del presente trabajo, en el que se utiliza la prueba del cometa para medir la genotoxicidad del glifosato en diferentes tipos celulares, no concuerdan con los obtenidos por otros autores que utilizan la misma prueba y que concluyen que este herbicida no induce rupturas de cadena sencilla en el ADN (37). No obstante, con lo observado en este estudio respecto a la citotoxicidad tanto aguda como crónica y a la genotoxicidad, se sugiere que el mecanismo de acción del glifosato no se limita únicamente a las plantas sino que puede alterar la estructura del ADN en otros tipos de células como son las de los mamíferos.

\section{Agradecimientos}

Los autores agradecen especialmente a Michael Plewa y Elizabeth Wagner (Department of Crop Sciences, University of Illinois) por su permanente asesoría y colaboración; a Ana Lucía Álvarez por su apoyo técnico. Así mismo, agradecemos el apoyo financiero brindado por Colciencias y por el Fondo de Investigaciones de la Facultad de Ciencias de la Universidad de los Andes.

\section{Conflicto de intereses}

Los autores declaramos que no existe ningún conflicto de intereses en los resultados de este trabajo.

\section{Financiación}

Del Instituto Colombiano para el Desarrollo de la Ciencia y la Tecnología "Francisco José de Caldas" (Colciencias), contrato No.163-2002 y del Fondo de Investigaciones de la Facultad de Ciencias de la Universidad de los Andes.

\section{Referencias}

1. Smith EA, Oehme FW. The biological activity of glyphosate to plants and animals: a literature review. Vet Hum Toxicol 1992;34:531-43.

2. Amrhein N, Deus B, Gehrke P, Steinrûcken HC. The site of the inhibition of the Shikimate pathway by glyphosate. Plant Physiol 1980;66:830-4.

3. Atkinson D. Toxicological properties of glyphosate. En: Grossbard E, Atkinson D, eds. The Herbicide Glyphosate. Toronto, Canada: Butterworth and Co. Ltd.; 1985. p.127-33. 
4. U.S.A. Environmental Protection Agency. Glyphosate. EPA-Integration Risk Information System (en línea) 1998 enero-diciembre. [Consultado 2003, junio 26]; disponible en: http://www.epa.gov/iris/subst/ 0057.htm.

5. Li AP, Long TJ. An evaluation of the genotoxic potential of glyphosate. Fundam Appl Toxicol 1988;10:537-46.

6. Williams GM, Kroes R, Munro IC. Safety evaluation and risk assessment of the herbicide Roundup and its active ingredient, glyphosate, for humans. Regul Toxicol Pharmacol 2000;31:117-65.

7. Daruich J, Zirulnik F, Gimenez MS. Effect of the herbicide glyphosate on enzymatic activity in pregnant rats and their fetuses. Environ Res 2001;85:226-31.

8. Dallegrave E, Mantese FD, Coelho RS, Pereira JD, Dalsenter PR, Langeloh A. The teratogenic potential of the herbicide glyphosate-Roundup in Wistar rats. Toxicol Lett 2003;142:45-52.

9. Clements C, Ralph S, Petras M. Genotoxicity of selected herbicide in Rana catesbeiana tadpoles using the alkaline single-cell gel DNA electrophoresis (comet) assay. Environ Mol Mutagen 1997;29:277-88.

10. Singh NP, McCoy MT, Tice RR, Schneider EL. A simple technique for quantitation of low levels of DNA damage in individual cells. Exp Cell Res 1988;175:184-91.

11. Hartmann A, Elhajoui A, Kiskinis E, Poetter F, Martus H.J, Fjaellman A et al. Use of the alkaline comet assay for industrial genotoxicity screening: comparative investigation with the micronucleus test. Food Chem Toxicol 2001;39:843-58.

12. Plewa MJ, Kargalioglu Y, Vankerk D, Minear RA, Wagner ED. Mammalian cell cytotoxicity and genotoxicity analysis of drinking water disinfection byproducts. Environ Mol Mutagen 2002;40:134-42.

13. Rojas E, Lopez MC, Valverde M. Single cell gel electrophoresis assay: methodology and applications. J Chromatogr B Biomed Sci Appl 1999;722:225-54.

14. Wagner ED, Rayburn AL, Anderson D, Plewa MJ. Analysis of mutagens with single cell gel electrophoresis, flow cytometry, and forward mutation assays in an isolated clone of Chinese hamster ovary cells. Environ Mol Mutagen 1998;32:360-8.

15. Tice RR, Agurell E, Anderson D, Burlinson B, Hartmann A, Kobayashi $\mathrm{H}$ et al. Single cell gel/comet assay: guidelines for in vitro and in vivo genetic toxicology testing. Environ Mol Mutagen 2000;35:206-21.

16. Kiskinis E, Suter W, Hartmann A. High throughput comet assay using 96-well plates. Mutagenesis 2002; 17:37-43.

17. Plewa MJ, Wagner ED, Jazwierska P, Richardson SD, Chen PH, McKague AB. Halonitromethane drinking water disinfection byproducts: chemical characterization and mammalian cell cytotoxicity and genotoxicity. Environ Sci Technol 2004;38:62-8.
18. Sorensen KC, Stucki JW, Plewa MJ. Comparative quantitative analysis of agricultural chemicals using a microplate mammalian cell cytotoxicity assay. Bull Environ Contam Toxicol 2003;70:1083-8.

19. Monroy CM, Cortés AC, Sicard DM, Plewa MJ, Groot H. In vitro evaluation of glyphosate-induced DNA damage in fibrosarcoma cells HT1080 and $\mathrm{CHO}$ cells. Environ Mol Mutagen 2004;44:216.

20. Anderson D, Yu TW, Phillips BJ, Schmezer P. The effect of various antioxidants and other modifying agents on oxygen-radical-generated DNA damage in human lymphocytes in the comet assay. Mutat Res 1994;307: 261-71.

21. U.S.A. Environmental Protection Agency. Reregistration eligibility decision (RED): glyphosate. US Environmental Protection Agency, Office of Prevention, Pesticides and Toxic Substances; 1993.

22. U.S.A. Environmental Protection Agency. Ecological levels of concern: a comparative analysis. US Environmental Protection Agency, Office of Prevention, Pesticides and Toxic Substances; 1995.

23. NTP. Technical report on toxicity studies of glyphosate (CAS No 1071-83-6) administered in dosed feed to F344/ N rats and B6C3F1 mice. Toxicity Reports Series Number 16, NIH Publication. Research Triangle Park, N.C.: Department of Health and Human Services, National Toxicology Program; 1992. p.92-3135.

24. Eisenbrand G, Pool-Zobel B, Baker V, Balls M, Blaauboer BJ, Boobis A et al. Methods of in vitro toxicology. Food Chem Toxicol 2002;40:193-236.

25. Aoki T, Sato D, Li Y, Takino T, Miyamori H, Sato H. Cleavage of apolipoprotein $\mathrm{E}$ by membrane-type matrix metalloproteinase- 1 abrogates suppression of cell proliferation. J Biochem 2005;137:95-9.

26. Fahling M, Perlewitz A, Doller A, Thiele BJ. Regulation of collagen prolyl 4-hydroxylase and matrix metalloproteinases in fibrosarcoma cells by hypoxia. Comp Biochem Physiol C Toxicol Pharmacol 2004;139: 119-26.

27. Banerji A, Chakrabarti J, Mitra A, Chatterjee A. Cell membrane-associated MT1-MMP-dependent activation of pro-MMP-2 in A375 melanoma cells. J Environ Pathol Toxicol Oncol 2005;24:3-17.

28. Bowman KK, Sicard DM, Ford JM, Hanawalt PC. Reduced global genomic repair of ultraviolet lightinduced cyclobutane pyrimidine dimers in simian virus 40-transformed human cells. Mol Carcinog 2000;29: 1724.

29. Lehmann AR. Nucleotide excision repair and the link with transcription. Trends Biochem Sci 1995;20:402-5.

30. Moriya M, Ohta T, Wanatabe K, Miyazawa T, Kato K, Shirasu Y. Further mutagenicity studies on pesticides in bacterial reversion assay systems. Mut Res 1983;116:185-216. 
31. Rank J, Jensen AG, Skov B, Pedersen LH, Jensen K. Genotoxicity testing of the herbicide Roundup and its active ingredient glyphosate isopropylamine using the mouse bone marrow micronucleus test, Salmonella mutagenicity test, and allium anaphase-telophase test. Mutat Res 1993;300:29-36.

32. Wildeman AG, Nazar RN. Significance of plant metabolism in the mutagenicity and toxicity of pesticides. Can J Genet Cytol 1982;24:437-49.

33. Lioi MB, Scarfi MR, Santoro A, Barbieri R, Salvemini $\mathbf{O}$, Di Berardino $\mathbf{F}$ et al. Cytogenetic damage and induction of pro-oxidant state in human lymphocytes exposed in vitro to glyphosate, vinclozolin, atrazine and DPX-E9636. Environ Mol Mutagen 1998;32:39-46.
34. Van de Waart IEJ. Evaluation of the ability of glyphosate to induce chromosome aberrations in cultured peripheral human lymphocytes. Unpublished report, NOTOX, The Netherlands.1995.

35. World Health Organization. Glyphosate. Environmental Health Criteria 1995;159:1-177.

36. Bolognesi C, Bonatti S, Degan V, Gallerani E, Peluso M, Rabón M et al. Genotoxic activity of glyphosate and technical formulation Roundup. J Agric Food Chem 1997;45:1957-62.

37. Lueken A, Juhl-Strauss U, Krieger G, Witte I. Synergistic DNA damage by oxidative stress (induced by $\mathrm{H} 2 \mathrm{O} 2$ ) and nongenotoxic environmental chemicals in human fibroblasts. Toxicol Lett 2004;147:35-43. 